\title{
Massage Therapy Can Prevent the Risk of Autism Spectrum Disorders in Children
}

\author{
Andy Martahan Andreas ${ }^{1}$, Ratna Djuwita ${ }^{1}$, Helda Helda ${ }^{1}$, Rini Sekartni ${ }^{2}$, Sri Hartati R. Suradijono ${ }^{3}$, Thjin Wiguna ${ }^{4}$ \\ Angela B. M. Tulaar ${ }^{5}$, Yusuf Kristianto ${ }^{6}$, Hendrik Hendrik ${ }^{7 *} \mathbb{D}$ \\ ${ }^{1}$ Community Epidemiology Study Program, Faculty of Public Health, University of Indonesia, Jakarta, Indonesia; ${ }^{2}$ Department of \\ Pediatrics and Development, Faculty of Medicine, University of Indonesia, Jakarta, Indonesia; ${ }^{3}$ Department of Developmental \\ Psychology, Faculty of Psychology, University of Indonesia, Jakarta, Indonesia; ${ }^{4}$ Department of Child Psychiatry, Faculty of \\ Medicine, University of Indonesia, Jakarta, Indonesia; ${ }^{5}$ Department of Medical Rehabilitation, Faculty of Medicine, University \\ of Indonesia, Jakarta, Indonesia; ${ }^{6}$ Health Polytechnic, Ministry of Health Jakarta 1, Jakarta, Indonesia; ${ }^{7}$ Department of \\ Physiotherapy, Health Polytechnic, Ministry of Health Makassar, Makassar, Indonesia
}

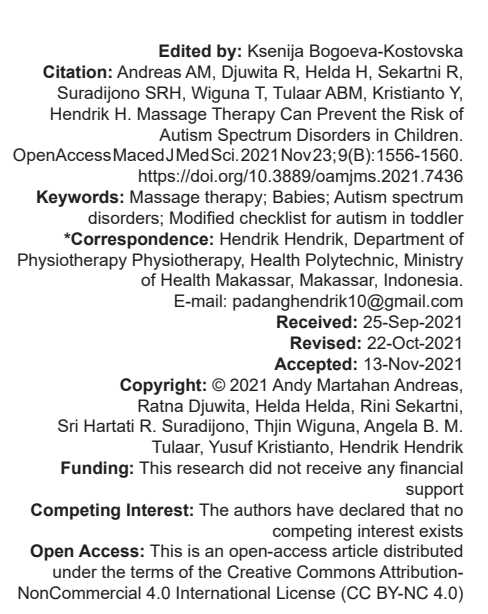

\section{Abstract}

BACKGROUND: The prevalence of human beings with autism spectrum issues in some parts of the world tends to make bigger, in Indonesia alone, accurate and complete data and information from human beings with autism spectrum disorders (ASD) are nonetheless missing, so it is feared that many children with risk symptoms of ASD do not get treatment early.

AIM: This research aims to prevent the risk of ASD in children through making use of massage therapy remedies based on evaluation of the Modified Checklist for Autism in Toddler (modified Chat [M-Chat]) ratings.

METHODS: This research is a quasi-experimental study with a time series design which was carried out from May 2019 to March 2020 at three health centers in the city of Jakarta. The analysis was carried out before and after the application of massage in a time series of four periods on ten children aged 18-36 months with M-Chat scores, and then analyzed by receiver operating characteristics to obtain a cutoff point to determine the risk status of ASD.

RESULTS: The results showed that there was an effect of massage therapy on the M-Chat score of children with ASD risk $p=0.004<0.05$ and changes in the M-Chat score of children with ASD risk experienced significant changes after massage in the third and fourth therapy periods with $p=0.005$ and $p=0.007<0.05$.

CONCLUSION: The results show that massage therapy can prevent of autism spectrum issues in children based on the Modified Checklist for Autism in Toddler (M-Chat)

\section{Introduction}

In the past decade, research on autism spectrum disorder (ASD) has received a lot of attention from experts in the field of welfare, especially in the field of child health. Autism spectrum issues begin from infancy to the age of 3 years [1]. Autism spectrum problems are existing from start and can be identified in children aged 18 months [2]. ASD from year to year tends to increase, but the exact incidence has not been obtained until now. Data on ASD are often obtained from hospitals, polyclinics, doctors' practices, special schools, or certain institutions, while data from research results in the community regarding the prevalence or incidence of ASD can still be obtained and accessed accurately. Autism is still less well known, especially in developing countries. The Ministry of Women's Empowerment and Child Protection of the
Republic of Indonesia critiques that in the world the incidence rate of autism is 1-2 per a thousand populace. In Canada, the prevalence of autism is $1 \%$ of 67,000 children aged 3-20 years, where males are more than females in a ratio of 4:1 [3]. According to the US Centers for Disease Control and Prevention, the occurrence of autism was once 14.6 per a thousand children aged 8 years in 2012 [4]. In Indonesia, it has accelerated from one per a thousand populace to eight per a thousand populace in 2009 and in 2015 it is estimated that 12,800 younger human beings have autism and 134,000 have autism spectrum [5]. Although this research has been studied from various aspects, the problem of ASD in other parts of the world is still high, both in developed and developing countries, including Indonesia.

Many solutions are offered in overcoming the problems of ASD, such as systemic psychotherapy, social therapy, structural focused therapy, and 
solutions with primary caregivers to massage therapy approaches [6], [7], [8], [9], [10], but the solution is not optimal because everything is done for children who have autism. Because the solution is carried out on infants who have experienced ASD, the solution measures only to overcome the psychosocial development disorders of children who have ASD.

Because the results of the research above are aimed at infants who have experienced ASD at an older age, the solution is only limited to treatment to reduce the limitations that occur in the psychosocial development of children [10], [11]. However, solutions to overcome the high risk of ASD cannot be achieved. Therefore, an intervention is needed as a solution to prevent the increase in risk factors for children under 36 months of age who have ASD.

In connection with the above, it is necessary to have an intervention in the form of massage therapy from the parents of the baby as a prevention effort in children aged 18-36 months who tend to risk ASD which can be measured based totally on the Modified Checklist for Autism in Toddler scores (modified Chat [M-Chat]). This research is necessary because massage therapy can be done anywhere and anytime by the baby's parents. Besides that, baby massage in Indonesian society is local wisdom that is carried out for generations [12], which socio-culturally is something that is usually done to increase body weight, sleep quality, and improve the ability to eat and breastfeed babies [11], [12]; however, now not aimed at stopping the prevalence of risk factors for ASD in children. Therefore, this research is very vital to do to stop the elevated hazard of autism spectrum issues in youngsters based totally on the M-Chat standards.

\section{Materials and Methods}

To decide the chance of autism spectrum issues in the sample, 904 socio-psychomotor and attentional life of children aged 18-36 months were screened to modify the $\mathrm{M}$-Chat score using receiver operating characteristic analysis to obtain cutoff points as the score in determining children's ASD. The standards for the risk status of autism spectrum issues primarily based on the modified M-Chat rating used are high risk > 49; risk of autism 24-49, and normal < 23 . The modified value of the $\mathrm{M}$-Chat score was used in screening carried out from May 2019 to March 2020 on 1685 children and obtained ten children $(0.6 \%)$ who had the risk of ASD. Determine the cutoff factors of the $\mathrm{M}$-Chat rating for every baby to decide the threat repute of autism spectrum problems as a pre-test rating earlier than the intervention. Then, the child is given massage therapy for 40 days which are divided into four periods, where each period takes 10 days. At the end of each period, the cutoff points of the M-Chat score were measured as the basis for determining the level of risk for ASD. The cutoff point value of the M-Chat score in the fourth period is used as the post-test value, so this research is an experimental study with a time-series design.

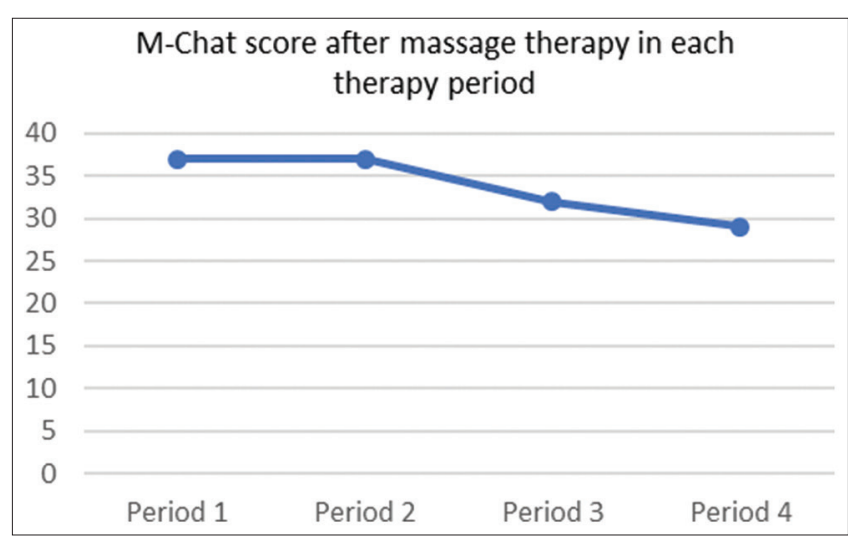

Figure 1: Changes in M-Chat scores period 1-4 on the application of massage therapy

All parents of children sampled in this study filled out informed consent. This research has been approved by the Health Research Ethics Committee of the University of Indonesia, Number: Ket-78/UN2.F1O/ PPM.00.02/2019.

To determine the effect of massage therapy on the level of risk of ASD, an analysis of the cutoff points of the M-Chat rating earlier than and after the intervention was carried out the usage of a paired t-test analysis. To determine changes in the M-Chat score or changes in risk status of ASD in each period of massage therapy, multivariate analysis with a general repeated measure was used. Differences between indices had been regarded statistically enormous at the probability $p<0.05$

\section{Results}

The results of the analysis of the characteristics of the sample data obtained that the age of 18-24 months had the highest number, namely, nine people $(90 \%)$ compared to the age of 25-36 months, namely, one person (10\%). On the gender factor, it showed that the sample was more in the male gender, namely, seven people $(70 \%)$ compared to the female sex, namely, three people (30\%). For threat elements for autism spectrum issues in children, it shows that other factors are greater, namely, nine people $(90 \%)$ than factors due to chromosomal abnormalities, which are one person $(10 \%)$. In terms of childbirth, generally, children who are at chance for autism spectrum issues have records of ordinary delivery, specifically eight humans (80\%) compared to other factors such as cesarean section, which are two people (20\%). Thus, it can be concluded 
that the sample of this study is generally children under 24 months of age with the most sex being male with the biggest causal factors being other factors outside of chromosomal abnormalities, infection, and the environment, with the most history of normal deliveries.

The results of the data analysis of the sample M-Chat scores in Table 1 show that in period 1 therapy the M-Chat value was $37.300+9.3814$ with a minimal value of 25 and a most of 58 . In therapy period 2 obtained a value of $37.300+9.3814$ with a minimum value of 25 and a most of 58 .

Table 1: M-Chat scores for infants aged 18-36 months for each therapy period

\begin{tabular}{llllll}
\hline Therapy time & $\mathrm{n}$ & Mean & $\mathrm{SD}$ & Minimum & Maximum \\
\hline Period I (days 1-10) & 10 & 37.300 & 9.3814 & 25 & 58 \\
Period II (days 11-20) & 10 & 37.300 & 9.3814 & 25 & 58 \\
Period III (days 21-30) & 10 & 32.500 & 9.3005 & 24 & 56 \\
Period IV (days 31-40) & 10 & 29.600 & 9.4187 & 23 & 54 \\
\hline
\end{tabular}

For therapy period 3 , the $\mathrm{M}$-Chat value is $32.500+9.3005$ with a minimum value of 24 and a maximum of 56, and in period 4 therapy, a M-Chat value of $29.600+9.4187$ is obtained with a minimum value of 23 and a maximum of 54 . Thus, it can be concluded that the M-Chat value in therapy periods 1 and 2 showed the same value and in therapy periods 3 and 4 decreased, meaning that the M-Chat score value changed in the form of a decrease after the baby was massaged after therapy periods 1 and 2 .

The results of statistical analysis with paired t-test on the M-Chat score on the risk of children with autism spectrum problems earlier than and after being given massage therapy for 40 days (four periods of therapy) showed that there was a difference in the $\mathrm{M}-\mathrm{Ch}$ at score with a significant value of $0.004<0.05$, where the baby's M-Chat score as a sample before massage therapy was $37.300+9.381$, while after being given massage therapy for 40 days (four periods) the M-Chat score was $29.600+9.418$ with a difference of 7700 , meaning that there was a decrease in the M-score value. Chat after being given massage therapy for 40 days (four periods of therapy). Thus, it can be concluded that massage therapy affects impacts lowering the danger of ASD.

The results of multivariate statistical tests with general reaped measures showed that there was a change in the $\mathrm{M}$-Chat score after massage therapy between therapeutic periods, wherein periods 3 and 1 there was a difference of -4.8 which indicated a significant difference with $p=0.005<0.05$. Likewise, between therapy periods 4 and 1 , there is a difference of -7.7 which indicates a significant difference with $p=0.007<0.05$, which means that massage therapy affects changes in the M-Chat score in therapy periods 3 and 4 . Thus, it can be concluded that massage therapy affects the $\mathrm{M}$-Chat score after being given therapy for 30-40 days. More details on the change in the child's M-Chat score after massage therapy in therapy periods 3 and 4.

\section{Discussion}

Autism spectrum ailment is a period used to describe a state of deficit in social communication and repetitive sensory-motor behavior that appear early in children related to a genetic issue and different motives [13]. This study was conducted on children aged 18-36 months who based on the results of screening using the M-Chat score had a tendency to risk autism spectrum issues. The results of the find out about acquired that the sample was generally children below 24 months of age, with the most sex being male with scattered factors being other factors outside of chromosomal abnormalities, infection, and the environment, with the most history of childbirth due to normal delivery (Table 2). This allows for the diagnosis of an ASD. The younger the child, the sooner a spectrum disorder is found. This is in line with the results of research by Towle et al., 2020, who state that the most children with ASD can be diagnosed at the age of 24 months, and it is even recommended to do a diagnosis at an early age [14]. The age of the sample is under the age of 24 months because this study was conducted before the child had autism by identifying risk factors for autism as early as possible. This is done by researchers in the hope that early intervention can be carried out in children to prevent the occurrence of more severe ASD. This age can also identify cognitive and language scores so that more positive results can be obtained [15]. The age of 24 months is the most appropriate age for diagnosing children at risk for ASD [16], [17]. For the gender factor, there were more males than females at risk for ASD. This has not been scientifically proven [18], but the results of the study did not show any differences between the sexes in the occurrence of ASD [19]. The male gender is estimated to be more at risk of ASD around 4:1 [20], due to the influence of parenting, which expects excessive behavior and social pressure than boys [18]. Furthermore, the female sex may be protective of social disabilities so that there is a lack of detection for diagnosis [13], [18], [21]. The causative factors show

Table 2: Analysis of sample characteristics based on age, gender, causative factors, and maternal history of childbirth

\begin{tabular}{lll}
\hline Variable & F & $\%$ \\
\hline Age (months) & 9 & \\
18-24 & 1 & 90 \\
$25-36$ & 10 & 10 \\
Total & & 100 \\
Gender & 7 & 70 \\
Male & 3 & 30 \\
Female & 10 & 100 \\
Total & & \\
Causative factor & 1 & 10 \\
Chromosomal & & \\
abnormalities & 0 & 0 \\
Infection & 0 & 0 \\
Environment & 9 & 90 \\
Etc & 10 & 100 \\
Total & & \\
Maternal birth history & 8 & 80 \\
$\quad$ Normal & 2 & 20 \\
Caesar & 0 & 0 \\
Tool Help & 10 & 100 \\
Total & & \\
\hline
\end{tabular}


that other factors are more dominant than chromosomal disorders, infection, and environmental factors. This is because the most parents do not understand the causes. Even the use of mobile devices that are not by official guidelines will cause health problems for children, including behavioral disorders, reduced attention, and increased aggressiveness [22], [23], [24]. Birth history shows that children born normally have the highest risk of ASD than cesarean deliveries. This can happen because the normal delivery process has many risks during and after childbirth. Risks in normal delivery can be in the form of maternal old age, narrow hips so that the baby is in a vacuum, or labor induction and hypertension [25], [26].

Massage therapy affects reducing the risk of ASD (Table 3). The mechanism can be achieved because gentle massage in children will cause stimulation and relaxation of the autonomic nerves as one of the physiological bases to provide a reflex effect on the autonomic system. The relaxing effect can occur when the child feels fear, anxiety, or pain or has an emotional reaction [27]. This happens because of massage, the hypothalamus will be stimulated by impulses to the spinal cord causing sympathetic release as a self-protection mechanism [28]. Massage can improve behavior, social, or communication skills as well as tactile and other sensory symptoms [29]. Massage therapy can reduce stress as a factor that affects the body's physiological and psychological changes [30].

Table 3: Analysis of M-Chat scores before and after giving massage therapy to children at threat for autism spectrum disorders

\begin{tabular}{|c|c|c|c|c|c|c|}
\hline \multirow[t]{3}{*}{ Variable } & \multicolumn{4}{|c|}{$\begin{array}{l}\text { Autism spectrum disorder } \\
\text { massage therapy }\end{array}$} & \multirow[t]{3}{*}{$\begin{array}{l}\text { Average } \\
\text { difference }\end{array}$} & \multirow[t]{3}{*}{$p$-value } \\
\hline & \multicolumn{2}{|l|}{ Before } & \multicolumn{2}{|l|}{ After } & & \\
\hline & Mean & SD & Mean & SD & & \\
\hline $\begin{array}{l}\text { The risk of children with } \\
\text { autism spectrum disorders }\end{array}$ & 37.300 & 9.381 & 29.600 & 9.418 & 7.700 & 0.004 \\
\hline
\end{tabular}

Changes in the M-Chat score occurred after the child was given massage therapy for 21-40 days (Tables 1 and 4). This mechanism occurs because with massage children will experience relaxation, not stress, and focus more on activities. Stress will affect the physiological and psychological systems of the body, causing an increase in the frequency of cardiac output, reducing peripheral and kidney blood flow so that children become unfocused, behavioral disorders, reduced attention, and increased aggressiveness [22], [23], [30], to increase the $\mathrm{M}-\mathrm{Chat}$ score, which means the child has a high risk of ASD. By giving massage therapy, children will be relaxed because massage therapy will overcome tactile disorders in children [29], besides massage therapy for 6 weeks will improve children's emotions, friendliness, showing higher face-to-face interplay behavior, reducing urinary stress (cortisol), and catecholamines (norepinephrine and epinephrine) as nicely as accelerated tiers of serotonin [31], as a result, the M-Chat score decreased and even became normal so that children reduced or even had no risk of developing ASD (Figure 1).
Table 4: Comparison of M-Chat scores after massage therapy between therapy periods

\begin{tabular}{llll}
\hline Therapy period & M-Chat after the massage therapy & Average difference & p-value \\
\hline Period 2 & $37.300 \pm 9.3814$ & 0.0 & - \\
Period 1 & $37.300 \pm 9.3814$ & & \\
Period 3 & $32.500 \pm 9.3005$ & -4.8 & 0.005 \\
Period 1 & $37.300 \pm 9.3814$ & -7.7 & \\
Period 4 & $29.600 \pm 9.4187$ & & 0.007 \\
Period 1 & $37.300 \pm 9.3814$ & \\
\hline
\end{tabular}

\section{Conclusion}

Massage therapy influences the child's M-Chat score so that a normal cutoff point score can be got which motives the threat of a child's ASD to become normal. It takes 21-40 days to do massage therapy on children to get the risk of a child's ASD to be normal based on the value of the M-Chat score.

\section{References}

1. Lord C, Elsabbagh M, Baird G, Veenstra-Vanderweele J. Autism spectrum disorder. Lancet. 2018;392(10146):508-20. https:// doi.org/10.1016/S0140-6736(18)31129-2

PMid:30078460

2. Kuban KC, O'Shea TM, Allred EN, Tager-Flusberg $\mathrm{H}$ Goldstein DJ, Leviton A. Positive screening on the modified checklist for autism in toddlers (M-CHAT) in extremely low gestational age newborns. J Pediatr. 2009;154(4):535-540.e1. https://doi.org/10.1016/j.jpeds.2008.10.011

PMid:19185317

3. Anagnostou E, Zwaigenbaum L, Szatmari P, Fombonne E, Fernandez BA, Woodbury-Smith $\mathrm{M}$, et al. Autism spectrum disorder: Advances in evidence-based practice. CMAJ. 2014;186(7):509-19. https://doi.org/10.1503/cmaj.121756 PMid:24418986

4. Diallo FB, Fombonne É, Kisely S, Rochette L, Vasiliadis HM Vanasse A, et al. Prevalence and Correlates of Autism Spectrum Disorders in Quebec: Prévalence et corrélats des troubles du spectre de l'autisme au Québec. Can J Psychiatry. 2018;63(4):231-9. https://doi.org/10.1177/0706743717737031 PMid:29056086

5. Labola YA. Autism Child Data Not Accurate? ResearchGate; 2018. Available from: https://www.researchgate. net/profile/yostan-labola-2/publication/329092028_data_child autism_notyet_accurate/links/5bf51da4a6fdcc3a8de-65e2a/ data-anak-autisme-belum-akurat.pdf [Last accessed on 2018 Nov 01].

6. Jordan SS, Turns B. Utilizing solution-focused brief therapy with families living with autism spectrum disorder. J Fam Psychother. 2016;27(3):155-70. https://doi. org/10.1080/08975353.2016.1199766

7. Zeina RM, Al-ayadhi L, Bashir S. Autism spectrum disorder Main problem waiting for solution in Kingdom of Saudi Arabia. Int J Med Health Sci. 2014;8(8):526-9.

8. Brockman M, Hussain K, Sanchez B, Turns B. Managing child behavior problems in children with autism spectrum disorders: Utilizing structural and solution focused therapy with primary caregivers. Am J Fam Ther. 2016;44(1):1-10. https://doi.org/10. 1080/01926187.2015.1099414

9. Lu WP, Tsai WH, Lin LY, Hong R Bin, Hwang YS. The beneficial 
effects of massage on motor developmentand sensory processing in young children with developmental delay: A randomized control trial study. Dev Neurorehabil. 2019;22(7):487-95. https:// doi.org/10.1080/17518423.2018.153 7317

PMid:30376388

10. Field T. Pediatric massage therapy research: A narrative review. Children (Basel).2019;6(6):78. https://doi.org/10.3390/ children6060078

PMid:31174382

11. Rambe KS. The effect of baby massage on the sleep quality of babies aged 0-6 months in Pasar Latong village, Lubuk Barumun district, Padang Lawas regency in 2019. ???. 2019;3(4):71-7. Available from: https://www.simantek.sciencemakarioz.org/ index.php/JIK/article/view/86

12. Yuniati I. Local wisdom baby massage for baby weight gain ???. 2021;2(2):93-104. Available from: http://www.ejournal.iwi. or.id/ojs/index.php/iwi/article/view/86

13. McLennan JD, Lord C, Schopler E. Sex differences in higher functioning people with autism. J Autism Dev Disord. 1993;23(2):217-27. https://doi.org/10.1007/BF01046216 PMid:8331044

14. Towle PO, Patrick PA, Ridgard T, Pham S, Marrus J. Is earlier better? The relationship between age when starting early intervention and outcomes for children with autism spectrum disorder: A selective review. Autism Res Treat. 2020;2020:7605876. https://doi.org/10.1155/2020/7605876 PMid:32832154

15. Perryman T, Watson LR, Chumney F. Predictors of the age of autism spectrum disorder diagnosis: A North Carolina cohort. Autism Dev Lang Impair. 2018;3:239694151775189. https://doi. org/10.1177/2396941517751892

16. Primo PG, Weber C, de la Paz MP, Fellinger J, Dirmhirn A, Holzinger D. Explaining age at autism spectrum diagnosis in children with migrant and non-migrant background in Austria. Brain Sci. 2020;10(7):448. https://doi.org/10.3390/ brainsci10070448

PMid:32674382

17. Leader G, Hogan A, Chen JL, Maher L, Naughton K, O'Rourke N et al. Age of autism spectrum disorder diagnosis and comorbidity in children and adolescents with autism spectrum disorder. Dev Neurorehabil. 2021;1:1-9. https://doi.org/10.1080/17518423.20 21.1917717

PMid:33934683

18. Begeer S, Mandell D, Wijnker-Holmes B, Venderbosch S, Rem D, Stekelenburg F, et al. Sex differences in the timing of identification among children and adults with autism spectrum disorders. J Autism Dev Disord. 2013;43(5):1151-6. https://doi. org/10.1007/s10803-012-1656-z

PMid:23001766

19. Horovitz M, Matson JL, Turygin N, Beighley JS. The relationship between gender and age of first concern in toddlers with autism spectrum disorders. Res Autism Spectr Disord. 2012;6(1):466-71. https://doi.org/10.1016/j.rasd.2011.06.017

20. Donovan J. Childbirth experiences of women with autism spectrum disorder in an acute care setting. Nurs Womens Health. 2020;24(3):165-74. https://doi.org/10.1016/j.nwh.2020.04.001

\section{PMid:32389581}

21. Holtmann M, Bölte S, Poustka F. Autism spectrum disorders: Sex differences in autistic behaviour domains and coexisting psychopathology. Dev Med Child Neurol. 2007;49(5):361-6. https://doi.org/10.1111/j.1469-8749.2007.00361.x PMid: 17489810

22. Tamana SK, Ezeugwu V, Chikuma J, Lefebvre DL, Azad MB Moraes TJ, et al. Screen-time is associated with inattention problems in preschoolers: Results from the CHILD birth cohort study. PLoS One. 2019;14(4):e0213995. https://doi. org/10.1371/journal.pone.0213995

PMid:30995220

23. van den Heuvel M, Ma J, Birkhoff CM, Koroshegyi C, Dai DW, Parkin PC, et al. Mobile media device use is associated with expressive language delay in 18-month-old children. J Dev Behav Pediatr. 2019;40(2):99-104. https://doi.org/10.1097/ DBP. 0000000000000630 PMid:30753173

24. Wahyuni AS, Siahaan FB, Arfa M, Alona I, Nerdy N. The relationship between the duration of playing gadget and mentalemotional state of elementary school students. Open Access Maced J Med Sci. 2019;7(1):148-51. https://doi.org/10.3889/ oamjms.2019.037

PMid:30740180

25. Polo-Kantola P, Lampi KM, Hinkka-Yli-Salomäki S, Gissler M, Brown AS, Sourander A. Obstetric risk factors and autism spectrum disorders in Finland. J Pediatr. 2014;164(2):358-65. https://doi.org/10.1016/j.jpeds.2013.09.044

PMid:24183209

26. Nelson KB. Prenatal and perinatal factors in the etiology of autism. Pediatrics. 1991;87(5):761-6.

\section{PMid:2020535}

27. Gallagher S, Varga S. Conceptual issues in autism spectrum disorders. Curr Opin Psychiatry. 2015;28(2):127-32.

PMid:25594417

28. Escalona A, Field T, Singer-Strunck R, Cullen C, Hartshorn K Brief report: Improvements in the behavior of children with autism following massage therapy. J Autism Dev Disord. 2001;31(5):513-6. https://doi.org/10.1023/a:1012273110194 PMid:11794416

29. Silva LM, Schalock M, Gabrielsen KR, Budden SS, Buenrostro M, Horton G. Early intervention with a parent-delivered massage protocol directed at tactile abnormalities decreases severity of autism and improves child-to-parent interactions: A replication study. Autism Res Treat. 2015;2015:904585. https://doi. org/10.1155/2015/904585

PMid:25878901

30. Kurebayashi LF, Turrini RN, de Souza TP, Takiguchi RS, Kuba G, Nagumo MT. Massage and reiki used to reduce stress and anxiety: Randomized clinical trial. Rev Lat Am Enfermagem. 2016;24:e2834. https://doi.org/10.1590/1518-8345.1614.2834 PMid:27901219

31. Field T. Massage therapy. Med Clin NorthAm. 2002;86(1):163-71. https://doi.org/10.1016/s0025-7125(03)00078-6

PMid:11795087 